\title{
DAMPED VIBRATION OF THE SYSTEM OF CHANGING THE CRANE BOOM RADIUS
}

\author{
Wojciech Sochacki, Marta Bold \\ Institute of Mechanics and Fundamentals of Machinery Design \\ Czestochowa University of Technology \\ Częstochowa, Poland \\ sochacki@imipkm.pcz.czest.pl,bold@imipkm.pcz.pl
}

\begin{abstract}
This study formulates and solves the problem of transverse damped vibration in the system of changing the boom radius in a truck crane with advanced cylinder design for controlling the boom radius. The dissipation of vibration energy in the model adopted in the study occurs as a result of internal damping of the viscoelastic material (rheological Kelvin-Voigt model) of the beams that model the system and movement resistance in the supports of the cylinder and crane boom to the bodywork frame of the crane. Damped frequencies of vibrations and degree of vibration amplitude decay were calculated. The study also presents eigenvalues of system vibration with respect to changes in damping coefficients and system geometry for a selected load.
\end{abstract}

Keywords: truck crane, damped vibration, eigenvalues

\section{Introduction}

The system of changing the boom radius in a truck crane represents the system with a high level of complexity and a series of studies have been devoted to the analysis of its dynamics. The monograph [1] and work [2] have been entirely focused on investigations of the dynamics and modelling of truck cranes and their components. Analysis of dynamic stability of truck crane was presented in the study [3], whereas the study [4] examined its free and parametric vibrations. The methods of positioning of load location and its effect on vibration of a truck crane were presented in the studies [5-7]. In most of the above studied, modelling of a cylinder that changes the boom radius was simplified, whereas the effect of damping has not been taken into consideration. The investigations concerning damped vibration have been discussed in [8-13]. The effect of small internal and external damping on stability of non-conservative beam systems was presented in [8]. The authors of the study [9] demonstrated the effect of internal damping on vibrations of a support beam with a mass attached to the free end of the beam. The study [10] presented the effect of constructional damping of supports on free vibrations in a simple 
Bernoulli-Euler beam. The study [11] examined damped vibrations of a simple beam, where damping in the system was represented by translational and rotational dampers.

This study concerns the analysis of damped vibrations in the system of changing the boom radius of a DST0285 truck crane. Previous studies in this field examined vibrations of the system with internal damping [12] and vibrations in the system with constructional damping of supports [13]. The dissipation of vibration energy in the model adopted occurs as a result of simultaneous internal damping of the viscoelastic material of the beam used in the model and the constructional damping in the locations of supports of the cylinder and crane boom with the bodywork frame of the crane. The constructional damping of supports was modelled using rotational viscous dampers. The results obtained were presented by means of three-dimensional graphs.

\section{Physical and mathematical models of the system}

The physical model of changes in the crane boom radius is presented in Figure 1. Changes in boom radius (boom inclination angle) are controlled by a hydraulic cylinder fixed to the rotational frame of the crane boom.

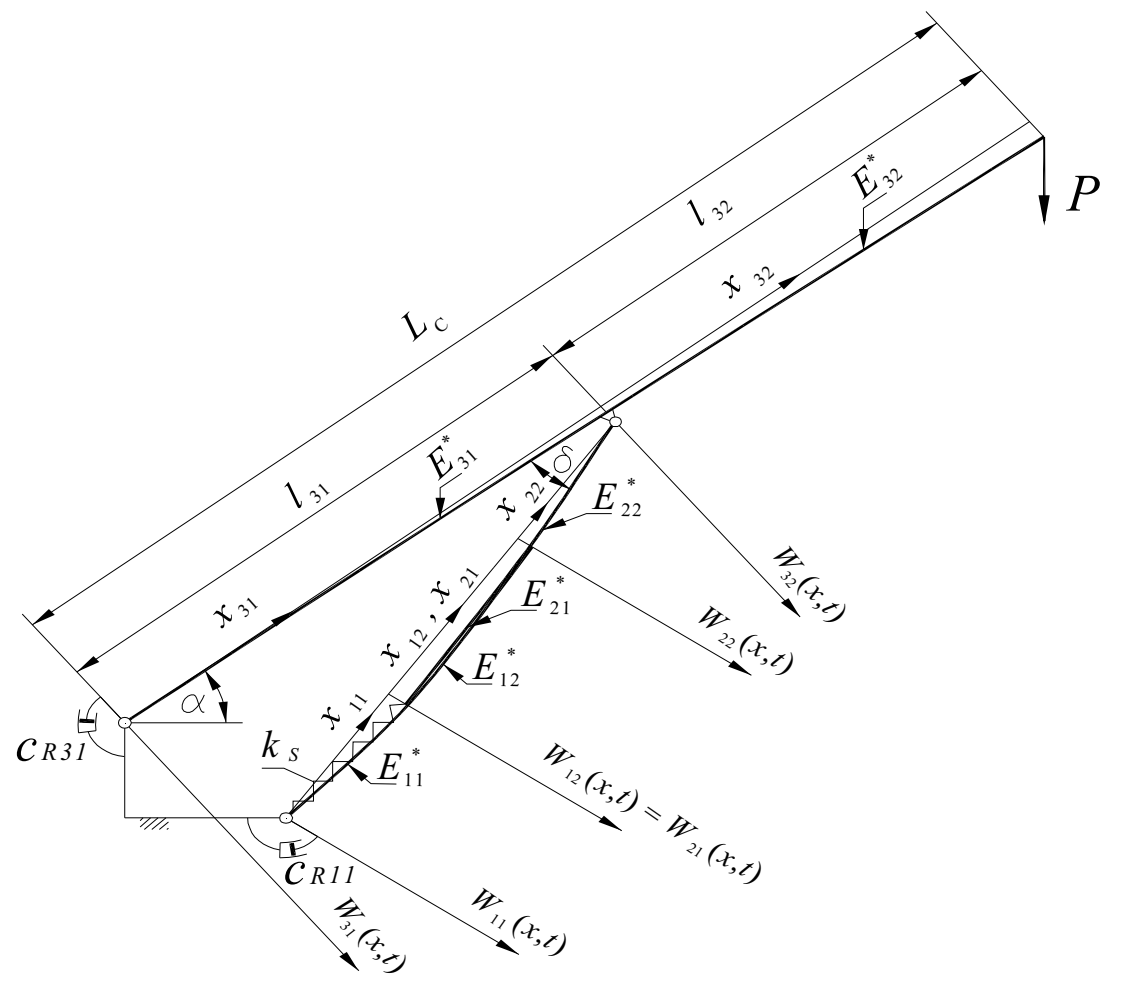

Fig. 1. Physical model of the system of changing the crane boom radius 
Formulation of the boundary problem was carried out using the Hamilton's principle:

$$
\delta \int_{t_{1}}^{t_{2}}(T-V) d t+\int_{t_{1}}^{t_{2}} \delta W_{N} d t=0
$$

where kinetic energy of the system $T$ is expressed by the equation:

$$
T=\sum_{m=1}^{3} \sum_{n=1}^{2} \frac{1}{2} \int_{0}^{l_{m n}} \rho_{m n} A_{m n}\left[\frac{\partial W_{m n}(x, t)}{\partial t}\right]^{2} d x_{m n}
$$

Potential energy of the system $V$ :

$$
\begin{aligned}
& V=\sum_{m=1}^{3} \sum_{n=1}^{2} \frac{1}{2}\left[\int_{0}^{l_{m n}} J_{m n} E_{m n}\left(\frac{\partial^{2} W_{m n}\left(x_{m n}, t\right)}{\partial x_{m n}^{2}}\right)^{2} d x_{m n}+\right. \\
& \left.-\int_{0}^{l_{m n}} P_{m n}(t)\left(\frac{\partial W_{m n}\left(x_{m n}, t\right)}{\partial x_{m n}}\right)^{2} d x_{m n}\right]+\frac{1}{2} k_{s}\left(\left.W_{31}\left(x_{31}, t\right) \sin \delta\right|^{x_{31}=l_{31}}\right)^{2}+ \\
& -\frac{1}{2} P_{p}\left(W_{32}\left(x_{32}, t\right)||^{x_{32}=l_{32}}\right)^{2}
\end{aligned}
$$

Components of the virtual work of non-conservative forces $W_{N}$ come from the dissipation forces that result from internal damping of the viscoelastic material $E_{m n}^{*}$ (rheological Kelvin-Voigt model) of the beams that model the system and for constructional damping in the cylinder support and $C_{R 31}$ and for constructional damping in the crane support $C_{R 11}$ :

$$
\begin{aligned}
& \delta W_{N}=-\left\{\sum_{m=1}^{3} \sum_{n=1}^{2} \int_{0}^{l_{m n}} J_{m n} E_{m n}^{*} \frac{\partial^{2}}{\partial x_{m n}^{2}}\left(\frac{\partial W_{m n}\left(x_{m n}, t\right)}{\partial t}\right) \delta \frac{\partial^{2} W_{m n}\left(x_{m n}, t\right)}{\partial x_{m n}^{2}} d x_{m n}+\right. \\
& +\left.\left.C_{R 11}\left(\frac{\partial}{\partial t}\right) \frac{\partial W_{11}\left(x_{11}, t\right)}{\partial x_{11}}\right|_{x_{11}=0} \delta \frac{\partial W_{11}\left(x_{11}, t\right)}{\partial x_{11}}\right|_{x_{11}=0} d x_{11}+ \\
& \left.+\left.\left.C_{R 31}\left(\frac{\partial}{\partial t}\right) \frac{\partial W_{31}\left(x_{31}, t\right)}{\partial x_{31}}\right|_{x_{31}=0} \delta \frac{\partial W_{31}\left(x_{31}, t\right)}{\partial x_{31}}\right|_{x_{31}=0} d x_{31}\right\}
\end{aligned}
$$


Performing the integration, using the commutative properties of these operations with respect to spatial variables and time and commutative properties of variational and differential operators and integration by parts and replacement of the equation (1) yield:

$$
\begin{aligned}
& \delta \int_{t_{1}}^{t_{2}}(T-V) d t+\int_{t_{1}}^{t_{2}} \delta W_{N} d t=\int_{t_{1}}^{t_{2}}\left\{\sum _ { m = 1 } ^ { 3 } \sum _ { n = 1 } ^ { 2 } \int _ { 0 } ^ { l _ { m n } } \left\{-J_{m n}\left(E_{m n}+E^{*}{ }_{m n} \frac{\partial}{\partial t}\right) \frac{\partial^{4} W_{m n}\left(x_{m n}, t\right)}{\partial x_{m n}^{4}}+\right.\right. \\
& \left.-\rho_{m n} A_{m n} \frac{\partial^{2} W_{m n}\left(x_{m n}, t\right)}{\partial t^{2}}-P_{m n}(t) \frac{\partial^{2} W_{m n}\left(x_{m n}, t\right)}{\partial x_{m n}^{2}}\right\} \delta W_{m n}\left(x_{m n}, t\right) d x_{m n}+ \\
& +\sum_{m=1}^{2} \sum_{n=1}^{2}\left\{J_{m n}\left(E_{m n}+E^{*}{ }_{m n} \frac{\partial}{\partial t}\right) \frac{\partial^{3} W_{m n}\left(x_{m n}, t\right)}{\partial x_{m n}^{3}}+\right. \\
& \left.+P_{m n}(t) \frac{\partial W_{m n}\left(x_{m n}, t\right)}{\partial x_{m n}}\right\}\left.\delta W_{m n}\left(x_{m n}, t\right)\right|_{x_{m n}=0} ^{x_{m n}=l_{m n}}+ \\
& +\left.P_{p} W_{32}\left(x_{32}, t\right) \delta W_{32}\left(x_{32}, t\right)\right|^{x_{32}=l_{32}}+\left.k_{S} W_{31}\left(x_{31}, t\right) \sin (\delta) \delta W_{31}\left(x_{31}, t\right)\right|^{x_{31}=l_{31}}+ \\
& +\left.\sum_{m=1}^{2} \sum_{n=1}^{2}\left\{-J_{m n}\left(E_{m n}+E_{m n}^{*} \frac{\partial}{\partial t}\right) \frac{\partial^{2} W_{m n}\left(x_{m n}, t\right)}{\partial x_{m n}^{2}}\right\} \delta \frac{\partial W_{m n}\left(x_{m n}, t\right)}{\partial x_{m n}}\right|_{x_{m n}=0} ^{x_{m n}=l_{m n}}+ \\
& +\left.\left.C_{R 11}\left(\frac{\partial}{\partial t}\right) \frac{\partial W_{11}\left(x_{11}, t\right)}{\partial x_{11}}\right|^{x_{11}=l_{11}} \delta \frac{\partial W_{11}\left(x_{11}, t\right)}{\partial x_{11}}\right|^{x_{11}=l_{11}}+ \\
& \left.+\left.\left.C_{R 31}\left(\frac{\partial}{\partial t}\right) \frac{\partial W_{31}\left(x_{31}, t\right)}{\partial x_{31}}\right|_{x_{31}=0} \delta \frac{\partial W_{31}\left(x_{31}, t\right)}{\partial x_{31}}\right|_{x_{31}=0}\right\} d t=0
\end{aligned}
$$

Equations of motion for individual beams in the model of changing the boom radius were denoted as:

$$
\begin{aligned}
& E_{m n} J_{m n} \frac{\partial^{4} W_{m n}(x, t)}{\partial x^{4}}+E_{m n}^{*} J_{m n} \frac{\partial^{5} W_{m n}(x, t)}{\partial x^{4} \partial t}+ \\
& +P_{m n} \frac{\partial^{2} W_{m n}(x, t)}{\partial x^{2}}+\rho_{m n} A_{m n} \frac{\partial^{2} W_{m n}(x, t)}{\partial t^{2}}=0
\end{aligned}
$$

where: $W_{m n}(x, t)$ - transverse displacements of beams, $E_{m n}$ - Young's moduli in beams, $E_{m n}^{*}$ - viscosity coefficients in beams, $A_{m n}$ - cross-sectional areas of beams, 
$J_{m n}$ - moments of inertia for cross-sectional areas of beams, $\rho_{m n}$ - beam material densities, $P_{m n}$ - longitudinal forces in beams used in the model of the crane boom and the cylinder for changing the boom radius $\left(P_{12}=0, P_{p}=P \cos \alpha\right), m=1,2,3$; $n=1,2 ; x$ - spatial coordinate, $t$ - time.

Solutions of equations (6) are in the form:

$$
W_{m n}(x, t)=w_{m n}(x) e^{i \omega^{*} t}
$$

where $\omega^{*}$ - integrated eigenvalue of the system, $\omega^{*}=\operatorname{Re}\left(\omega^{*}\right)+i \operatorname{Im}\left(\omega^{*}\right), i=\sqrt{-1}$.

Substitution of (7) into (6) leads to:

$$
w_{m n}^{I V}(x)+\beta_{m n}^{2} w_{m n}^{I I}(x)-\gamma_{m n} w_{m n}(x)=0
$$

where:

$$
\gamma_{m n}=\frac{\rho_{m n} A_{m n} \omega^{* 2}}{\left(E_{m n}+i E_{m n}^{*} \omega^{*}\right) J_{m n}} ; \beta_{m n}=\sqrt{\frac{P_{m n}}{\left(E_{m n}+i E_{m n}^{*} \omega^{*}\right) J_{m n}}} ; \beta_{12}=0
$$

Geometrical boundary conditions and continuity conditions are given by:

$$
\begin{aligned}
& w_{11}(0)=0, \quad w_{11}\left(l_{11}\right)=w_{12}(0), \quad w_{11}^{I}\left(l_{11}\right)=w_{12}^{I}(0), \\
& w_{12}(0)=w_{21}(0), \quad w_{12}\left(l_{12}\right)=w_{21}\left(l_{21}\right), \quad w_{21}\left(l_{21}\right)=w_{22}(0), \\
& w_{21}^{I}\left(l_{21}\right)=w_{22}^{I}(0), \quad w_{22}\left(l_{22}\right)=w_{31}\left(l_{31}\right) \cos \delta, \quad w_{31}(0)=0, \\
& w_{31}\left(l_{31}\right)=w_{32}(0), \quad w_{31}^{I}\left(l_{31}\right)=w_{32}^{I}(0)
\end{aligned}
$$

The natural boundary conditions of the system studied:

$$
\begin{aligned}
& \left(E_{11}+i E_{11}^{*} \omega^{*}\right) J_{11} w_{11}^{I I}(0)=-C_{R 11} i \omega^{*} w_{11}^{I}(0), \\
& \left(E_{12}+i E_{12}^{*} \omega^{*}\right) J_{12} w_{12}^{I I}\left(l_{12}\right)=0, \\
& \left(E_{12}+i E_{12}^{*} \omega^{*}\right) J_{12} w_{12}^{I I}(0)=\left(E_{11}+i E_{11}^{*} \omega^{*}\right) J_{11} w_{11}^{I I}\left(l_{11}\right), \\
& \left(E_{21}+i E_{21}^{*} \omega^{*}\right) J_{21} w_{21}^{I I}(0)=0, \\
& \left(E_{11}+i E_{11}^{*} \omega^{*}\right) J_{11} w_{11}^{I I I}\left(l_{11}\right)+P_{11} w_{11}^{I}\left(l_{11}\right)-\left(E_{12}+i E_{12}^{*} \omega^{*}\right) J_{12} w_{12}^{I I I}(0)+ \\
& -\left(E_{21}+i E_{21}^{*} \omega^{*}\right) J_{21} w_{21}^{I I I}(0)-P_{21} w_{21}^{I}(0)=0, \\
& \left(E_{12}+i E_{12}^{*} \omega^{*}\right) J_{12} w_{12}^{I I I}\left(l_{12}\right)+\left(E_{21}+i E_{21}^{*} \omega^{*}\right) J_{21} w_{21}^{I I I}\left(l_{21}\right)+ \\
& -\left(E_{22}+i E_{22}^{*} \omega^{*}\right) J_{22} w_{22}^{I I I}(0)=0,
\end{aligned}
$$




$$
\begin{aligned}
& \left(E_{31}+i E_{31}^{*} \omega^{*}\right) J_{31} w_{31}^{I I}(0)=-C_{R 31} i \omega^{*} w_{31}^{I}(0), \\
& \left(E_{22}+i E_{22}^{*} \omega^{*}\right) J_{22} w_{22}^{I I}\left(l_{22}\right)=0, \\
& \left(E_{32}+i E_{32}^{*} \omega^{*}\right) J_{32} w_{32}^{I I I}\left(l_{32}\right)+P_{32} w_{32}^{I}\left(l_{32}\right)=-P_{p}, \\
& \left(E_{32}+i E_{32}^{*} \omega^{*}\right) J_{32} w_{32}^{I I}\left(l_{32}\right)=0 \\
& \left(E_{22}+i E_{22}^{*} \omega^{*}\right) J_{22} w_{22}^{I I}(0)=\left(E_{21}+i E_{21}^{*} \omega^{*}\right) J_{21} w_{21}^{I I}\left(l_{21}\right), \\
& \left(E_{31}+i E_{31}^{*} \omega^{*}\right) J_{31} w_{31}^{I I}\left(l_{31}\right)=\left(E_{32}+i E_{32}^{*} \omega^{*}\right) J_{32} w_{32}^{I I}(0), \\
& \left(E_{31}+i E_{31}^{*} \omega^{*}\right) J_{31} w_{31}^{I I I}\left(l_{31}\right)-\left(E_{32}+i E_{32}^{*} \omega^{*}\right) J_{32} w_{32}^{I I I}(0)+ \\
& +\left[\left(E_{22}+i E_{22}^{*} \omega\right) J_{22} w_{22}^{I I I}+P_{22} w_{22}^{I}\right] \cos \delta-k_{S} w_{31}\left(l_{31}\right) \sin \delta=0
\end{aligned}
$$

The solution for the equations ( 8 ) is given by:

$$
w_{m n}(x)=C_{1 m n} e^{\lambda_{m n} x}+C_{2 m n} e^{-\lambda_{m n} x}+C_{3 m n} e^{i \bar{\lambda}_{m n} x}+C_{4 m n} e^{-i \bar{\lambda}_{m n} x}
$$

where:

$$
\lambda_{m n}=\sqrt{-\frac{\beta_{m n}^{2}}{2}+\sqrt{\frac{\beta_{m n}^{4}}{4}+\gamma_{m n}}} ; \bar{\lambda}_{m n}=\sqrt{\frac{\beta_{m n}^{2}}{2}+\sqrt{\frac{\beta_{m n}^{4}}{4}+\gamma_{m n}}}
$$

Substitution of (11) to (10a-b) yields a homogeneous system of equations with respect to unknown constants $C_{k m n}$, which, in the matrix form, can be written as:

$$
[A]\left(\omega^{*}\right) C=0
$$

where:

$$
A\left(\omega^{*}\right)=\left[a_{p q}\right] ; \quad(p, q=1,2 . .24) ; C=\left[C_{k m n}\right]^{\mathrm{T}} ; k=1,2-4
$$

The system has a non-trivial solution if the determinant of the coefficient matrix (with constant $C_{k m n}$ ) equals zero.

$$
\operatorname{det} A\left(\omega^{*}\right)=0
$$

Finding integrated eigenvalues of the matrix $A\left(\omega^{*}\right)$ leads to the determination of damped vibration frequency and the degree of vibration amplitude decay in the system studied. Depending on the solution adopted, the real and imaginary parts of the eigenvalues can be positive or negative and can represent damped vibration frequency or the degree of vibration amplitude decay. In this study, the real part $\operatorname{Re}\left(\omega^{*}\right)$ of the solution corresponds to the damped vibration, whereas the imaginary part $\operatorname{Im}\left(\omega^{*}\right)$ characterizes the degree of vibration amplitude decay. Presentation of the results was based on positive values of the real and imaginary parts of solutions. 


\section{Numerical calculation results}

Calculations were carried out for the system of controlling changes in crane boom radius in a DST0285 truck crane loaded with the force of $P=2.5 \mathrm{kN}$. The loading force adopted is the highest permissible load of a crane with maximum extension of the crane boom and minimal angle of inclination. Computations were carried out for the data contained in Table 1.

Dimensionless damping parameters were used in the study: $\eta$ for internal damping of viscoelastic material of beams, $\mu_{11}$ for constructional damping in the cylinder support, and $\mu_{31}$ for constructional damping in the crane boom support.

$$
\mu_{11}=\frac{C_{R 11}}{L_{S} \sqrt{\rho_{11} A_{11}\left(E_{11}+i E_{11}^{*} \omega^{*}\right) J_{11}}} ; \mu_{31}=\frac{C_{R 31}}{L_{C} \sqrt{\rho_{31} A_{31}\left(E_{31}+i E_{31}^{*} \omega^{*}\right) J_{31}}}
$$

and:

$$
\eta=\frac{E_{m n}^{*}}{c E_{m n}} ; \quad c^{2}=L_{U}{ }^{4} \frac{\sum_{m, n} \rho_{m n} A_{m n}}{\sum_{m, n} E_{m n} J_{m n}} ; \quad L_{U}=L_{C}+L_{S}
$$

$L_{C}, L_{S}$ - total lengths of the crane boom and cylinder.

Physical and geometrical parameters of the model

\begin{tabular}{|l|c|}
\hline \multicolumn{1}{|c|}{ Parameter } & Value \\
\hline Length of the fixed component of the crane boom [m] & 7.95 \\
\hline Length of the retractable component of the second crane boom [m] & 8.3 \\
\hline Length of the retractable component of the third crane boom [m] & 8.2 \\
\hline Set stroke of telescopic cylinder [m] & variable \\
\hline External height of the basic component of the crane boom [m] & 0.596 \\
\hline External height of the 2/3 component of the crane boom [m] & $0.517 / 0.448$ \\
\hline Internal height of the basic component of the crane boom [m] & 0.585 \\
\hline Internal height of the 2/3 component of the crane boom [m] & $0.509 / 0.441$ \\
\hline External width of the basic component of the crane boom [m] & 0.397 \\
\hline External width of the 2/3 component of the crane boom [m] & $0.355 / 0.311$ \\
\hline Internal width of the basic component of the crane boom [m] & 0.39 \\
\hline Internal width of the 2/3 component of the crane boom [m] & $0.348 / 0.304$ \\
\hline Cylinder outer diameter [m] / Cylinder inner diameter [m] & $0.277 / 0.25$ \\
\hline Piston outer diameter [m] / Piston inner diameter [m] & $0.16 / 0.128$ \\
\hline Material density in boom crane and cylinder [kg/m $\left.{ }^{3}\right]$ & 7860 \\
\hline Density of the liquid in the cylinder [kg/m $\left.{ }^{3}\right]$ & 890 \\
\hline Young modulus for the material of the boom crane and cylinder [Pa] & $2.1 \times 10^{11}$ \\
\hline Liquid shear modulus [Pa] & $1.25 \times 10^{9}$ \\
\hline
\end{tabular}


The results of the calculations are presented in Figures 2 to 8. Due to substantial differences in the values between real and imaginary parts of eigenvalues, the results were presented in different figures. Similarly, different figures were used to present considerable differences in the first and second eigenvalue.

The relationships between the first $\omega_{1}$ (a) and the second $\omega_{2}$ (b) frequency of system vibration and changes in the angles of its inclination $\alpha$ and total length of the crane boom $L_{C}$ without damping in the system are presented in Figure 2.

a)

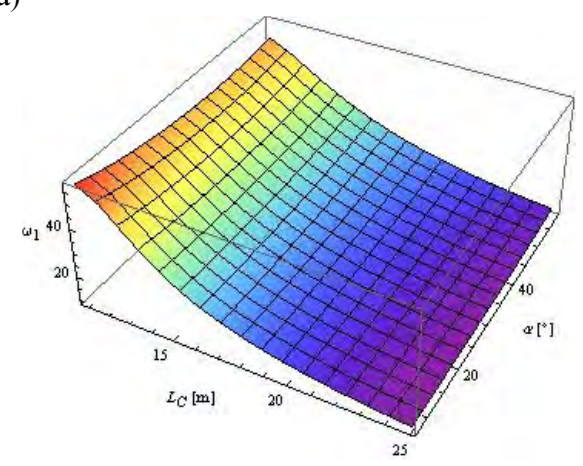

b)

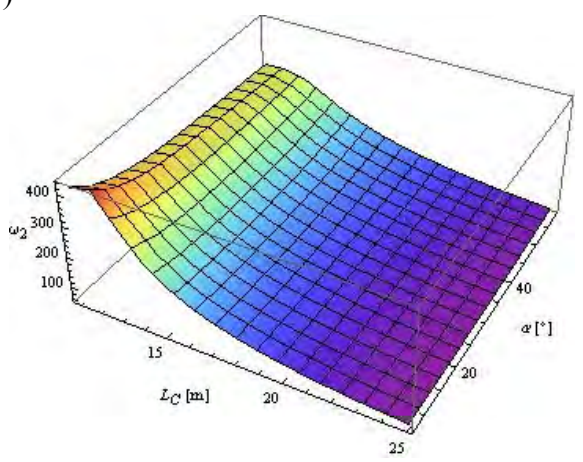

Fig. 2. Relationship between the first (a) and the second (b) frequency of the system of changing the boom radius and total boom length $L_{C}$ and angles of its inclination $\alpha$ without damping

a)

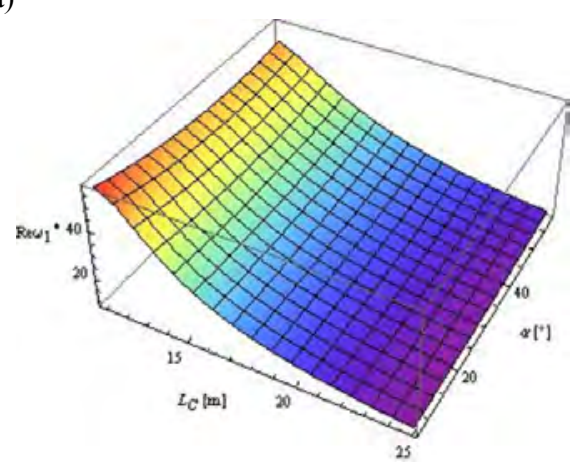

b)

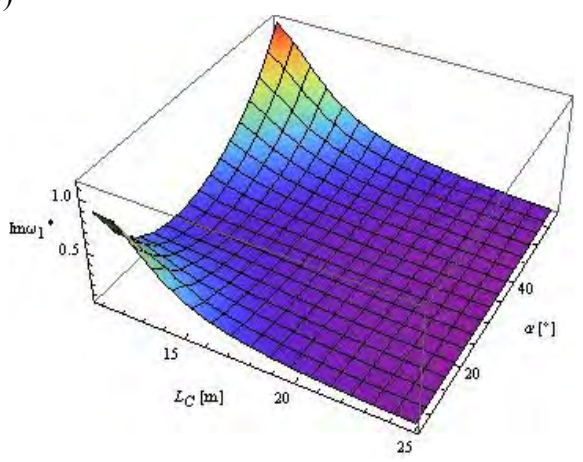

Fig. 3. Relationship between the first eigenvalue (real parts (a) and imaginary parts (b)) in the system of changing the boom radius and total boom length $L_{C}$ and angles of its inclination $\alpha$

The relationship of the real part $\operatorname{Re}\left(\omega^{*}\right)$ and the imaginary part $\operatorname{Im}\left(\omega^{*}\right)$ of the first and second eigenvalue of the system for changing the boom radius with total length of the crane boom $L_{C}$ and angle of inclination $\alpha$ is presented in Figures 3a, b, $4 \mathrm{a}$ and $\mathrm{b}$. Calculations were carried out for damping coefficients of $\eta=0.001$ and $\mu_{11}=\mu_{31}=0.4$. 
a)

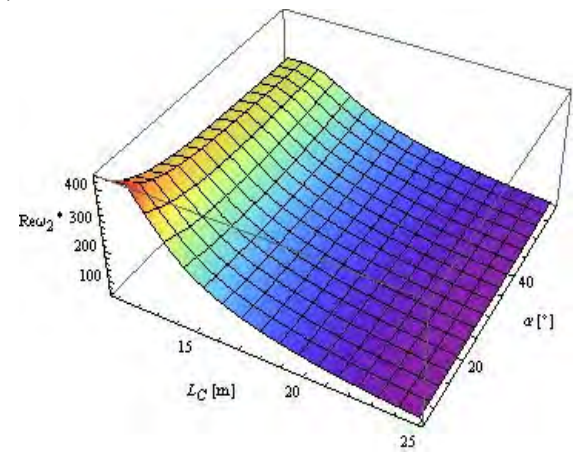

b)

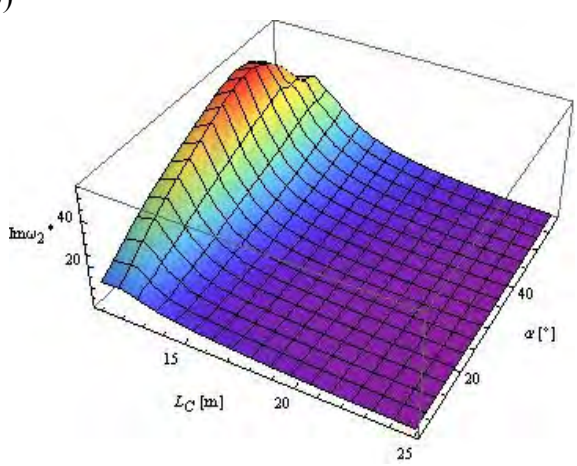

Fig. 4. Relationship between the second eigenvalue (real parts (a) and imaginary parts (b)) in the system of changing the boom radius and total boom length $L_{C}$ and the angles of its inclination $\alpha$

Figures $5 \mathrm{a}, \mathrm{b}$ and $6 \mathrm{a}, \mathrm{b}$ present the dependence of the real and imaginary parts of the first and second eigenvalues of the system of changing the boom radius on simultaneous changes in internal damping coefficient $\eta$ and constructional damping coefficient $\mu=\mu_{11}=\mu_{31}$ with crane inclination angle $\alpha=41^{\circ}$ and total crane boom length of $L_{C}=11.89 \mathrm{~m}$.

a)

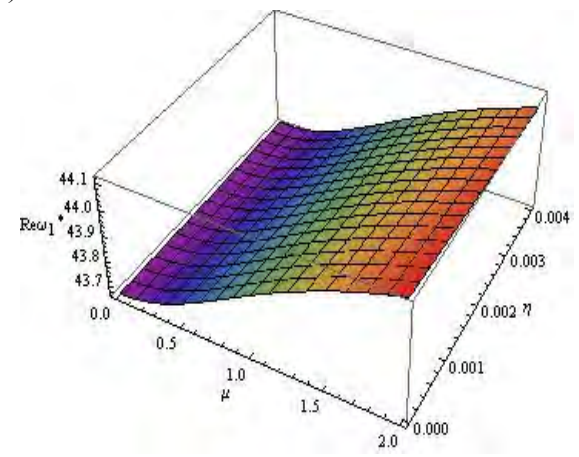

b)

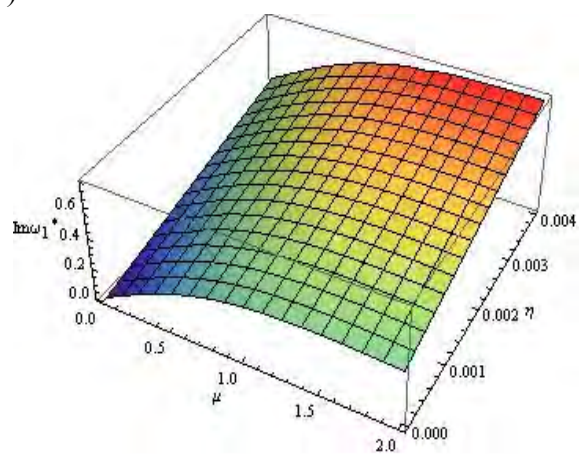

Fig. 5. Relationship between the first eigenvalue (real parts (a) and imaginary parts (b)) of the system of changing the crane boom and damping coefficients $\eta$

$$
\text { and } \mu=\mu_{11}=\mu_{31}
$$

Further investigations were focused on determination of the dependence of the first and the second eigenvalue of the system of changing the boom radius on changes in constructional damping coefficient $\mu=\mu_{11}=\mu_{31}$ and changes in total length of the crane boom $L_{C}$ for internal damping coefficient of $\eta=0.001$. Due to insignificant changes in the values of real parts with respect to the system without damping, Figures $7 \mathrm{a}$ and $\mathrm{b}$ present only $\mathrm{f}\left(\operatorname{Im}\left(\omega^{*}\right)\right)$. 
a)

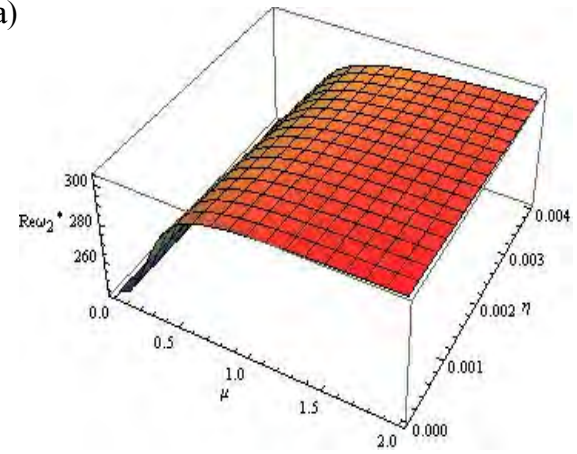

b)

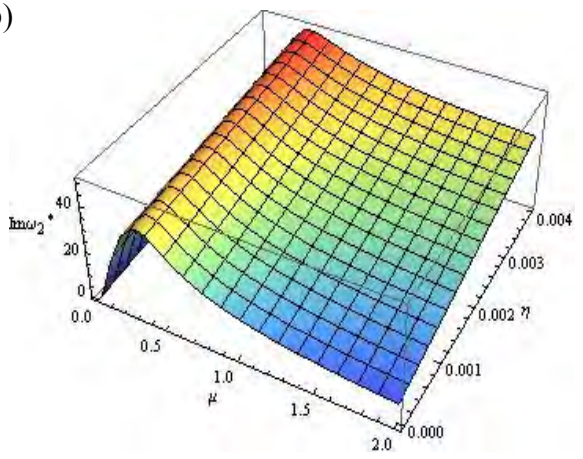

Fig. 6. Relationship between the second eigenvalue (real parts (a) and imaginary parts (b)) of the system of changing the crane boom and damping coefficients $\eta$ and $\mu=\mu_{11}=\mu_{31}$

a)

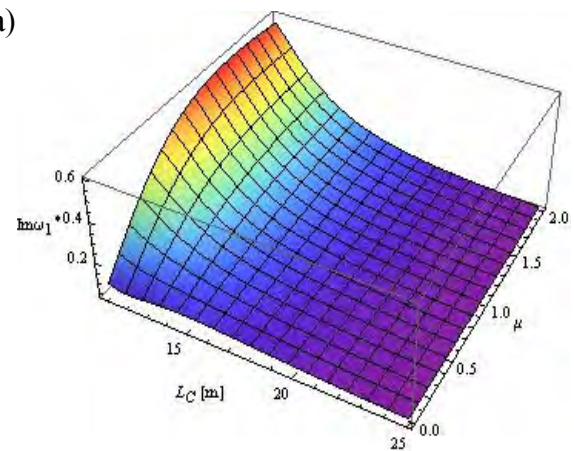

b)

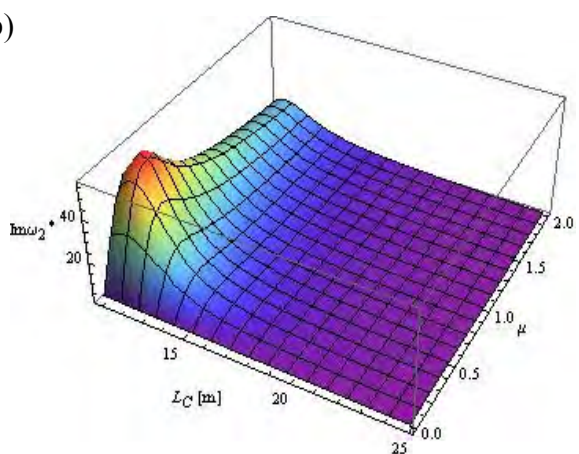

Fig. 7. The relationship of the imaginary part of the first (a) and second (b) eigenvalue of the system of crane boom change on total crane boom length $L_{C}$ and damping coefficient $\mu$

Figures $8 \mathrm{a}$ and $\mathrm{b}$ present the dependence of the imaginary part of the first and the second eigenvalue of the system of changing the boom range on changes in internal damping coefficient $\eta$ and changes in total length of the crane boom $L_{C}$ with constructional damping coefficient of $\mu=\mu_{11}=\mu_{31}=0.4$.

a)

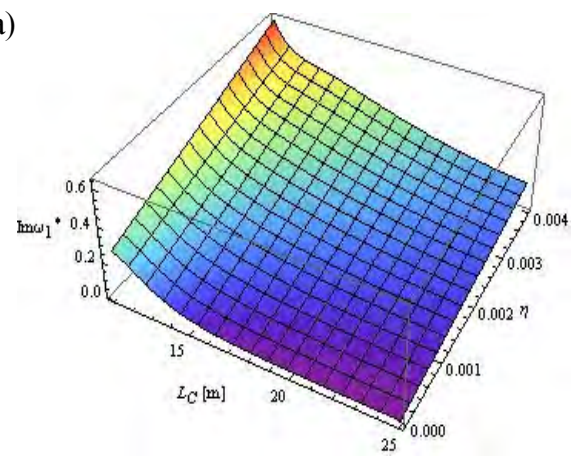

b)

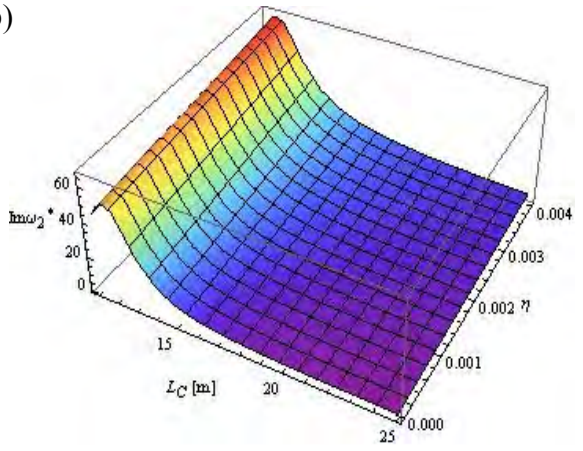

Fig. 8. The relationship of the imaginary part of the first (a) and second (b) eigenvalue of the system of crane boom change on total crane boom length $L_{C}$ and damping coefficient $\eta$ 
Limitation of the scope of the study to the analysis of changes in the two first eigenvalues of the system for changing the crane boom radius with changes in geometry and damping in the system results from their fundamental importance to engineering practice.

\section{Conclusions}

This study presented a beam model of a system of telescopic crane boom and hydraulic cylinder designed based on the actual truck DST0285 system. The study examined the effect of geometry of the damped system with the load adopted on its eigenvalues and the effect of simultaneous internal damping and constructional damping of the supports on eigenvalues with selected geometry of the system. The study demonstrated that taking damping in the system into consideration causes similar changes in the frequencies of damped vibrations with changes in system geometry (Figs. 3, 4) as in the system without damping (Fig. 2). Substantial changes can be observed in the degree of vibration amplitude decay, both the first and the second eigenvalue $\operatorname{Im}\left(\omega^{*}\right)$ in the case of changes in the length of crane boom $L_{C}$. Similarly, significant changes occur for coefficient $\operatorname{Im}\left(\omega^{*}\right)$ with changes in the crane boom inclination angle $\alpha$. The decrease of vibration amplitude of the system is represented by the increase of the degree of vibration amplitude decay. In other words, this coefficient characterizes the damping ability of such a system. The constructional damping of supports with selected value of internal vibration causes considerably higher changes in eigenvalues of the system than in the opposite case (change in the value of coefficient $\eta$ with selected value of $\mu_{11}$ and $\mu_{31}$ ). An increase in constructional damping causes the increase in the values of the degree of vibration amplitude decay $\operatorname{Im}\left(\omega^{*}\right)$ to maximum values, $\operatorname{Im}\left(\omega^{*}\right) \rightarrow 0$ where $\mu_{1 l}$ and $\mu_{3 l} \rightarrow \infty$ (Fig. 6b). The degree of determination of the angle of inclination of the crane boom (and, consequently, the degree of cylinder extension) and the length of crane boom extension for which the degree of vibration amplitude decay is the highest allows for determination of optimum lengths of the cylinder and the crane boom with respect to minimum vibration amplitudes in the system. Therefore, the use of rotational dampers can be considered as an additional method of controlling the dynamics of the system studied.

\section{Acknowledgements}

This research was supported by the Ministry of Science and Higher Education in 2014, Warsaw, Poland.

\section{References}

[1] Posiadała B., Modeling, identification and research of dynamic models of truck-cranes, WNT, Warsaw 2005. 
[2] Chin C., Nayfeh A.H., Abdel-Rahman E., Nonlinear dynamics of a boom crane, Journal Vibration Control 2001, 7, 199-220.

[3] Sochacki W., The dynamic stability of a laboratory model of a truck crane, Thin-Walled Structures 2007, 45, 927-930.

[4] Sochacki W., Tomski L., Free and parametric vibration of the system: telescopic boomhydraulic cylinder (changing the crane radius), The Archive of Mechanical Engineering 1999, $46,257-271$.

[5] Maczyński A., Positioning and stabilization of the load position of elevated work platforms, The University of Bielsko-Biala, Theses 2005, 14.

[6] Geisler T., Sochacki W., Modelling and research into the vibrations of truck crane, Scientific Research of the Institute of Mathematics and Computer Science 2011, 10(1), 49-60.

[7] Kilicaslan S., Balkan T., Ider S.K., Tipping load of mobile cranes with flexible booms, Journal of Sound and Vibration 1999, 223(4), 645-657.

[8] Kirillov O.N., Seyranin A.O., The effect of small internal and external damping on the stability of distributed non-conservative systems, Journal of Applied Mathematics and Mechanics 2005, 69(4), 529-552.

[9] Gürgöze M., Doğruoğlu A.N., Zeren S., On the eigencharacteristics of a cantilevered viscoelastic beam carrying a tip mass and its representation by a spring-damper-mass system, Journal of Sound and Vibration 2007, 301(1-2), 420-426.

[10] Oliveto G., Santini A., Tripodi E., Complex modal analysis of flexural vibrating beam with viscous end conditions, Journal of Sound and Vibration 1997, 200(3), 327-345.

[11] Krenk S., Complex modes and frequencies in damped structural vibrations, Journal of Sound and Vibration 2004, 270, 981-996.

[12] Sochacki W., Bold M., Vibration of crane radius change system with internal damping, Journal of Applied Mathematics and Computational Mechanics 2013, 12(2), 97-103.

[13] Sochacki W., Bold M., Influence of structural damping of supports on vibrations of the system telescopic boom - hydraulic cylinder of crane radius change, Modelling in Engineering 2013, $47(16), 172-178$. 